\title{
Removal modelling in ecology
}

\author{
Oscar Rodriguez de Rivera ${ }^{1 * \diamond}$, Rachel McCrea ${ }^{1 \odot}$
}

1 Statistical Ecology @ Kent, National Centre for Statistical Ecology. School of Mathematics, Statistics and Actuarial Science, University of Kent, Canterbury, CT2 $7 \mathrm{FS}, \mathrm{UK}$.

These authors contributed equally to this work.

*O.Ortega@kent.ac.uk

\begin{abstract}
Removal models were proposed over 80 years ago as a tool to estimate unknown population size. Although the models have evolved over time, in essence, the protocol for data collection has remained similar: at each sampling occasion attempts are made to capture and remove individuals from the study area. Within this paper we review the literature of removal modelling and highlight the methodological developments for the analysis of removal data, in order to provide a unified resource for ecologists wishing to implement these approaches. Models for removal data have developed to better accommodate important feature of the data and we discuss the shift in the required assumption for the implementation of the models. The relative simplicity of this type of data and associated models mean that the method remains attractive and we discuss the potential future role of this technique.
\end{abstract}

\section{Author summary}

Since the introduction of the removal in 1939, the method has being extensively used by ecologists to estimate population size. Although the models have evolved over time, in essence, the protocol for data collection has remained similar: at each sampling occasion attempts are made to capture and remove individuals from the study area. Here, we introduce the method and how it has been applied and how it has evolved over time. Our study provides a literature review of the methods and applications followed by a review of available software. We conclude with a discussion about the opportunities of this model in the future.

\section{Introduction}

One of the most interesting problems for the ecologist is the estimation of the density of a particular animal species [1] and a tremendous diversity of techniques are available for estimating the size of populations [2-4]. Despite frequent refinements to make some of the more sophisticated techniques more realistic for particular situations (see for example, [5-9]) the removal method remains exceptionally popular.

Removal (or depletion) sampling is a commonly used method to estimate abundance of animal populations [10-13]. Removal models have been used to estimate population size, not only for many species including birds [14], mammals [15], and fish [16], but also for epidemiological applications [17-19]. 
Removal models are ideally suited to estimating the number of invasive species as they coincide with desirable management (i.e. the reduction or eradication of populations) [20] and the method has recently been adopted as a conservation management tool for example for mitigation translocations [12,21]. Models that use data from management actions need to account for variations in removal effort as these data are unlikely to be standardised across events [20]. [22] showed that removal models that account for removal effort are effective at estimating abundance, particularly when removal rates are high.

The classic removal model was introduced by [23] and [24], motivated by a theory developed by [1]. This model relied on the assumption of population closure and constant detection probability, meaning that the animals are assumed to be available for capture with the same probability throughout the study and there are no births, deaths or migration during the study. The basic removal model results in a geometric decline in the expected number of captured individuals over time. This classic removal model is a special case of model $M_{b}$ for closed populations which allows for a behavioural response to initial trapping [5].

\section{Overview of the paper}

Within this paper we have conducted a systematic literature review of removal modelling in ecology. We describe the methods applied in the systematic review and the aspects of interest. We present the results obtained from the literature analyses, highlighting the key methodological advances which have been made in this field and a review of software which has been used to fit removal models. The paper concludes with a discussion about the future role of removal modelling in ecology.

\section{Materials and methods}

\section{Literature Search}

This systematic review followed the PRISMA (Preferred Reporting Items for Systematic Reviews and Meta-Analyses), statement as a guide [25]. The bibliographic search was performed using the SciVerse Scopus (https://scopus.com), ISI Web of Science (https://webofknowledge.com), and Google Scholar (https://scholar.google.com) databases. Papers published between 1939 and the cut-off date 01 July 2019 with the terms "Removal model" or "Removal method" and "population" in the title, keywords, or abstract were included. Non-English publications, and papers reporting removal methods focused on cleaning procedures were excluded from our search. The process of selecting papers to include in our review started with a screening of the abstract. Articles were excluded if they mentioned the keyword "removal model/method" for justification or discussion without implementing a removal model as part of the study. Thus, only the papers that reported applications, methodological advances of removal models or removal study design were retained for the analysis (Fig 1).

\section{Fig 1. PRISMA flowchart.}

\section{Data Analysis}

Features and parameters of each study were categorised and compiled into a database of removal model publications. We identified the details that were reported in the 104 reviewed publications and provided a descriptive summary of the essential details that need to be reported in published removal models (see Table 1). 


\begin{tabular}{ll}
\hline Category & Definition \\
\hline Year of publication & Year of publication as it appears in the final print \\
\hline Reference & Author-year citation style \\
\hline Species & Scientific name of the species included in the analysis \\
\hline Taxonomic Group & $\begin{array}{l}\text { Taxonomic group of the species included in the anal- } \\
\text { ysis (Class and Order) }\end{array}$ \\
\hline Research goal & Aim of the study (practical or methodological) \\
\hline Journal & Name of the journal where the study was published \\
\hline Subject area & Research area of the journal \\
\hline
\end{tabular}

Table 1. Parameters used to categorise Removal models included within the database

\section{Results}

\section{Synthesised Findings}

The reviewed literature was published from 1939 to 2019 and interestingly there have historically been long gaps in publications on this topic. However in recent years there has been a more constant stream of published papers, suggesting a resurgence of interest in the method (Fig 2). This is potentially an indication of the role of removal modelling in studies of reintroduction, especially when translocated individuals are removed from endangered populations [26], and the adaptations of model collection protocols to adopt a "removal" design for other data types such as occupancy and distance sampling, as will be discussed in "Adapting sampling schemes using removal theory" Section.

Fig 2. Papers published since 1939 by category. Papers published since 1939 by category (application or methodological) and ecosystem (aquatic, terrestrial or aerial

A strong representation of removal model publications was observed in the fields of Statistics (29 publications), Fisheries and Ecology journals (20 papers each of the disciplines) and 13 papers published in ornithological journals.

\section{Methodological Contributions}

\section{Early model developments}

The basic principle of the removal method is that a constant sampling effort will remove a constant proportion of the population present at the time of sampling. Thus, if the total population size is $N$ and $p$ denotes the probability of capture of an individual, the expected number of captures will be given by: $p N, p(N-p N)$ and $p[N-p N-p(N-p N)]$ for the first, second and third sampling occasions, respectively. Population estimates can be obtained either by plotting catch per unit effort of collection as a function of total previous catch (see for example $[1,27,28]$ ) or by obtaining maximum likelihood estimates $[23,24,29,30]$.

This model can be formalised by defining the corresponding likelihood function. Suppose $x_{t}$ denotes the number of individuals captured at sampling occasion $t=1, \ldots, T$, where $T$ denotes the number of sampling occasions.

Using a binomial-formulation, if $N_{t}$ individuals are still in the study at sampling occasion $t$, we can define the probability of removing $x_{t}$ individuals by

$$
\operatorname{Pr}\left(x_{t} \mid N_{t}, p_{t}\right)=\left(\begin{array}{c}
N_{t} \\
x_{t}
\end{array}\right) p^{x_{t}}(1-p)^{N_{t}-x_{t}}
$$


where $N_{1}=N$ and $N_{t}=N-\sum_{k=1}^{t-1} x_{k}$ for $t \geq 2$. Then, the probability of observing $x_{1}, \ldots, x_{T}$ is given by

$$
L\left(N, p ; x_{1}, \ldots, x_{T}\right)=\operatorname{Pr}\left(x_{1}, \ldots, x_{T} \mid N, p\right)=\prod_{t=1}^{T}\left(\begin{array}{c}
N_{t} \\
x_{t}
\end{array}\right) p^{x_{t}}(1-p)^{N_{t}-x_{t}} .
$$

Alternatively, we could specify that the $N$ individuals within the population belong to one of $T+1$ categories: either they are captured on one of occasion $1, \ldots, T$, or they could never be captured. Let $\pi_{t}$ denote the probability that an individual is captured at occasion $t$

$$
\pi_{t}=(1-p)^{t-1} p
$$

and let $\pi_{0}$ denote the probability that an individual is never captured:

$$
\pi_{0}=(1-p)^{T}
$$

Let $n$ denote the number of individuals never captured, which is given by $n=N-\Sigma_{t=1}^{T} x_{t}$, then the likelihood can be expressed as:

$$
L\left(N, p ; x_{1}, \ldots, x_{T}\right)=\operatorname{Pr}\left(x_{1}, \ldots, x_{T} \mid N, p\right)=\left(\begin{array}{c}
N \\
x_{1}, \ldots, x_{T}, n
\end{array}\right) \prod_{t=1}^{T} \pi_{t}^{x_{t}} \pi_{0}^{n} .
$$

Early developments of removal models were methodological in nature, to overcome issues which these days are simple to deal with because of computing power. [24] formalised the conditional binomial removal model of [23], providing an asymptotic variance of the abundance estimator. Further, they demonstrated how graphical methods can be used to estimate the parameters of capture and abundance. The likelihood of [23] is weighted with a beta prior by [31], which results in estimators with lower bias and variance. [32] proposed an improved confidence interval for abundance for small populations, whilst [33] proved that the profile log-likelihood for the removal model is unimodal and demonstrated that the likelihood-ratio confidence interval for the population size has acceptable small-sample coverage properties. Similarly, [34] proposes a profile likelihood approach for estimating confidence intervals which showed improved performance.

\section{Validity of model assumptions}

The model assumptions required for these early models were very restrictive. Specifically, capture probability, $p$ is assumed to be constant both across all individuals and for each sampling period. [23,24,29,30] have typically included tests of assumptions or information on necessary sample sizes in their studies. [13] included a table of percentage errors to be expected if $p$ varies during sampling and [5] offered alternative ways to estimate $N$ if $p$ varied for a wide class of closed population capture-recapture models, however it is not possible to fit many of these to removal data which has only one occasion of capture. [35], noting that the assumptions of the removal model are often violated, proposed the non-parametric jackknife estimator as an alternative to the removal model.

[31] proposed a standard test that combines testing for addition or deletions to the population with testing for equal catchability. The test entails examining trends in the catch vectors: "When the expected third catch as determined from the first two catches is larger than the observed third catch, emigration or a decreasing probability of capture is indicated. When the opposite condition exists, immigration or an increase in the probability of capture is indicated". Both the presence and absence of trends yields 
ambiguous information. Significant trends in the catch vectors can be caused by the population being open or by unequal catchability. An absence of trends implies either that the assumptions were met or that migration balanced changing probabilities of capture over time.

[36] indicates that unequal catchability tends to be the rule in biological populations. Hence testing for equal catchability is crucial unless one adapts the model. Assuming that equal catchability exists when it does not leads to underestimation of the population size. One procedure that avoids this bias is to identify subsets of the population that are equally catchable and to obtain separate population estimates for each subset [37]. However, because such subdivision of the data greatly decreases the precision of the estimate of the total population size, one should not divide the population unnecessarily if the assumption of equal catchability of all the individuals is met. Therefore, employing a test of equal catchability is a crucial step in any population analysis, even if failure to reject the null hypothesis of equal catchability is an ambiguous result [38].

Two aspects of equal catchability are important for the removal method: equal catchability among groups and equal catchability in all sampling occasions. The first is tested analogously to the test for marked and unmarked captures. If groups with different catchability are identified, separate population size estimates are made for each such group. Individual differences in catchability unrelated to a particular group membership are still possible, but [32] showed that unless these differences are great, their effect on the population estimate is small. [39] investigated the robustness of the removal model to varying behaviours exhibited by fish using simulation.

The second assumption, that catchability remains constant in all sampling periods can be tested by the chi-square test given by [24] or further test given by [5] or [40]. Conclusions drawn from any of these tests will be accurate only if the population remains closed during sampling. Use of a barrier if possible, is again desirable, or independent verification by sampling of marked animals [37].

The closure assumption of the removal model has been relaxed in [41], where a model was proposed which allows for population renewal through birth/immigration as well as for population depletion through death/emigration in addition to the removal process. The arrivals of new individuals are modelled by an unknown number of renewal groups and a reversible jump MCMC approach is used to determine the unknown number of groups. Within this paper however it is assumed that any emigration from the population is permanent, and this assumption has been relaxed in [12] which presents a robust design, multilevel structure for removal data using maximum likelihood inference. The implemented hidden Markov model framework [42], allows individuals to enter and leave the population between secondary samples. A Bayesian counterpart to this robust design model is presented in [43].

\section{Change in ratio, index-removal and catch-effort models}

Change in ratio models for population size estimation are closely related to removal models $[44,45]$. The model requires that the population can be sub-divided into distinct population classes and the removals will be performed in such a way that the ratio of removals of the sub-populations will be the same as the underlying ratio of the sub-classes within the population.

We can generalise the basic removal model likelihood function of Eq (2) by extending the definition of the parameters and the summary statistics. Specifically, suppose the population is sub-divided into $G$ mutually exclusive and exhaustive groups, and let $N(g)$ denote the unknown abundance of sub-population $g=1, \ldots, G$. We now record $x_{t}(g)$ individuals of sub-population $g$ being removed at occasion $t$. The likelihood becomes, 


$$
L\left(N, p ; x_{1}, \ldots, x_{T}\right)=\prod_{t=1}^{T} \prod_{g=1}^{G}\left(\begin{array}{c}
N_{t}(g) \\
x_{t}(g)
\end{array}\right) p^{x_{t}(g)}(1-p)^{N_{t}(g)-x_{t}(g)} .
$$

where $N_{1}(g)=N(g)$ and $N_{t}(g)=N(g)-\sum_{k=1}^{t-1} x_{k}(g)$ for $t \geq 2$.

Catch-effort models are a straight-forward extension of basic removal models which allow capture probability to be related to sampling effort. If catch per unit effort declines with time, then regressing accumulated removals by catch per unit effort allows the starting population to be estimated. This approach however strongly relies on the assumption that if more effort is put into capturing the individuals then a higher proportion of the population will be caught and if this is not satisfied estimators might be appreciably biased [46]. More generally we can extend the removal likelihood of Equation 2 to define a functional form of capture probability:

$$
L\left(N, p_{t} ; x_{1}, \ldots, x_{T}\right)=\operatorname{Pr}\left(x_{1}, \ldots, x_{T} \mid N, p\right)=\prod_{t=1}^{T}\left(\begin{array}{c}
N_{t} \\
x_{t}
\end{array}\right) p_{t}^{x_{t}}\left(1-p_{t}\right)^{N_{t}-x_{t}} .
$$

where $p_{t}$ is the capture probability at occasion $t$ which can be linked to a recorded covariate of survey effort, denoted by $w_{t}$. Possible forms for the functional form might be $\operatorname{logit}\left(p_{t}\right)=\alpha+\beta w_{t}$, where $\alpha$ and $\beta$ are parameters to be estimated, or $p_{t}=1-\exp ^{-\theta w_{t}}$, where $\theta$ is a single parameter to be estimated has been used for fisheries applications where $w_{t}$ denotes the amount of time spent fishing. Alternatively if $w_{t}$ denotes the number of traps on occasion $t$ and each animal is assumed to be caught in any trap with probability $\theta, p_{t}=1-(1-\theta)^{w_{t}}$ [4]. Indeed the logistic form of time-dependent capture probability can also be used to model time-variation in capture probability as a function of climatic conditions - see for example [47].

When sampling is with replacement and the sampling efforts are known, [48] modelled the survey sampling process as a Poisson point process where each animal is counted at random with respect to increments of sampling effort and it is assumed that the encounter probabilities for each individual are independent. [49] propose a class of catch-effort models which allow for heterogeneous capture probabilities.

The index-removal method makes use of the decline in a measure of relative abundance due to a known removal. The relative abundance is measured in surveys before and after the removal [50]. [51] proposed an index-removal estimator which accounts for seasonal variation in detection.

\section{Further model developments}

[52] demonstrates why auxiliary information is beneficial in removal studies and how to incorporate the extra information into the model and [14] extended the idea of incorporating sub-class level information by proposing a conditional likelihood approach for incorporating auxiliary variables. Capture probabilities are directly estimated from the conditional likelihood and then abundance estimates can be obtained using a Horvitz-Thompson-like approach.

[53] relaxed the assumption of [23] that traps are not limited in capacity by developing a model in which traps have a reduced capacity to catch once they have been filled. The model assumes that the probability that a specific animal will be caught is proportional to the number of traps that are unoccupied and is often referred to as the proportional trapping model.

Continuous-time removal models were proposed in [54] and the proportional trapping model and continuous time framework were combined in [55]. Further [56] 
and [57] extended the continuous time proportional trapping model to account for known ratios of sub-populations, thus generalising the change-in-ratio approach.

The theory of analysing multiple types of data in an integrated model within ecology has gained traction in recent years - see for example [58]. Early ideas of combining data types has been found in the removal literature. For example, [37] proposed combining capture-recapture and removal methods for fish removals when sampling is over a limited study period and [59] showed how the proportional trapping model can be extended to include data on non-target species.

Removal models have been presented as a class of hierarchical models, for example [16] present a hierarchical removal model where the sites are assumed to have several distinct sub-sites located spatially. Suppose removals occur at $S$ sites, then records are made of $x_{s t}$, the number of individuals removed from site $s=1, \ldots, S$ at occasion $t=1, \ldots, T$. Following the multinomial form of the likelihood of Equation 3 the probability of observing a sequence of removal counts, $\mathbf{x}_{\mathbf{s}}=\left\{x_{s 1}, \ldots, x_{s T}\right\}$ from site $s$ is given by

$$
f\left(\mathbf{x}_{\mathbf{s}} \mid N_{s}, p_{s}\right)=\left(\begin{array}{c}
N_{s} \\
x_{s 1}, \ldots, x_{s T}, n_{s}
\end{array}\right) \prod_{t=1}^{T}\left\{p_{s}\left(1-p_{s}\right)\right\}^{x_{s t}}\left(1-p_{s}\right)^{n_{s}},
$$

where $N_{s}$ denotes the abundance at site $s, p_{s}$ denotes the capture probability at site $s$ and $n_{s}=N_{s}-\sum_{t=1}^{T} x_{s t}$. Within the hierarchical formulation, a probabilistic formulation, defined by density function $g(N \mid \psi)$, with parameter $\psi$, specifies the variation in abundance among the $S$ spatially distinct sub-populations in the sample. The site-specific removal counts (Equation 6) can be combined with this model by integrating over possible values of $N_{s}$ :

$$
\mathrm{p}\left(\mathbf{x}_{\mathbf{s}} \mid \psi, \mathrm{p}_{\mathrm{s}}\right)=\sum_{N_{s}=\sum_{t} x_{s t}}^{\infty} f\left(\mathbf{x}_{\mathbf{s}} \mid N_{s}, p_{s}\right) g\left(N_{s} \mid \psi\right)
$$

The likelihood function is then the product over the observations from the $S$ sites, which assuming independence is defined by

$$
L\left(\psi, p_{1}, \ldots, p_{S} \mid \mathbf{x}_{\mathbf{1}}, \ldots, \mathbf{x}_{\mathbf{S}}\right)=\prod_{s=1}^{S} p\left(\mathbf{x}_{\mathbf{s}} \mid \psi, p_{s}\right) .
$$

This model is in fact a multinomial N-mixture model [60] and it has been shown that the removal $\mathrm{N}$-mixture model outperforms the standard $\mathrm{N}$-mixture model using simulation [61]. In practice, a value $K$ has been used in place of the infinite sum in equation 8 when evaluating the likelihood, however what value of $K$ is appropriate is subjective, and it has been shown there can be some problems with proposed values [62]. [63] has demonstrated that the multinomial N-mixture model for removal data, with negative binomial mixing distribution, has a closed-form likelihood and therefore no numerical approximations are required to fit the model.

\section{Adapting sampling schemes using removal theory}

Little work has been found which investigates study design for removal surveys. [64] explored how to optimally allocate total sampling effort for multiple removal sites by maximising the Fisher information of the constant capture probability in the classic removal model. This approach was extended by [65] to allocate effort between primary and secondary sampling occasions within the robust design removal model [12].

An adaptation of survey design for various data types have been augmented with the concept of removal studies. For example, [66] described a time-removal model that 
treats subsets of the survey period as independent replicates in which birds are 'captured' and mentally removed from the population during later sub-periods. This method has been implemented in many subsequent papers, see for example [67,68]. Further, the removal study design has been proposed for occupancy surveys [69], whereby once a site has been observed as occupied by a species no further surveys are required [70]. [71] developed a spatially explicit temporary emigration model permitting the estimation of population density for point count data such as removal sampling, double-observer sampling, and distance sampling.

\section{Applications}

From the papers we reviewed three ecosystems were identified (Figure 2) based on the species analysed. Almost half of the applied studies were focused on aquatic ecosystems (marine and fresh water); followed by flying species $(\mathrm{n}=24)$ and the rest of the applied studies analysing terrestrial ecosystems. However partitioning the papers by taxonomic group shows that the most common group are bird applications, with 23 papers identified. However, it should be noted that many of these applications use other data types but with adapted sampling design as described earlier [14,66,72-92]. Removal methods are clearly important in fisheries research and applications are presented in [93-110]. The papers analysing data from mammals are [1,5,20,111-121]. There are a further six papers analysing data from amphibians: [122-127] and [51] analysed crustaceans. Insects have being analysed in three papers: [128-130] and the less common applications included annelids [131] and Holothuroidea [132]. Three papers presented applications about human disease [17-19] and we included these in our analysis as the aim of the study was to estimate the proportion of an affected population which is an aim in common with ecological applications.

\section{Software}

There has been a considerable amount of recent work on developing software to make complex statistical models accessible to the wider ecological community. Much software has been developed to estimate population parameters, including abundance and demographic parameters which account for imperfect detection.

Capture [5], was developed to compute estimates of capture probability and population size for closed population capture-recapture data and given the basic removal model is a special case of closed capture-recapture model $M_{b}$, Capture can be used to fit the geometric removal model. RCapture [133] is an R package [134] for capture-recapture experiments. Rcapture can fit models for capture-recapture models but as well as standard open, closed and robust-design versions of these models based on multinomial likelihoods it is the only software which also implements a log-linear modelling algorithm to estimate the parameters.

Program Mark [135] provides a wide-range of models which can be fitted to more than 65 different data types to estimate several population parameters from the encounters of marked animals. Typically, parameters are obtained by method of maximum likelihood estimation through numerical methods (Newton-Raphson by default). However, an MCMC algorithm has been added to provide estimates using a Bayesian framework [136]. [137] demonstrate how removal models can be fitted using Program Mark for fisheries data. RMark [138] is a software package for the R computing environment that was designed as an alternative interface that can be used in place of Program Mark's graphical-user-interface to describe models with a typed formula so that models do not need to be defined manually through the design matrix. At the time of writing RMark supports fitting 97 of the 155 models available in Program Mark. R packages marked [139] and unmarked [140] can also be used to fit the standard removal 
model and multinomial N-mixture removal model, respectively - see [61]. There is also more specialised software that has arisen for specific applications. Removal Sampling v2 [141] was designed to estimate population size from removal data and [105] apply this software in order to analyse the effectiveness of stream sampling methods for capturing invasive crayfish.

In addition there is of course well-known software which accommodates the removal study design when fitting models to other data types. In particular Presence and RPresence [142] for occupancy surveys and Distance [143] for distance sampling.

\section{Discussion}

Early removal models were simplistic and did not adequately account for potential variability exhibited by the underlying population, however computational and methodological advances give the possibility of more complex models, increasing opportunities, scenarios and accuracy in population estimation. The framework we have presented here is designed to assimilate the use of removal models in order to assist future practitioners in the effective application of removal models.

In our review we have not only presented a list of papers published, differentiating application and methodological advances, but also we have explained the evolution of the model. We have shown how the model has been developed since [1] presented the first case with the evolution in likelihood function from the basic to, for example, that proposed by [49], accounting for heterogeneous capture probability, and more recently the work of [63], theoretically developing the multinomial N-mixture model for removal data.

We have shown how the model assumptions have been adapted, trying to fit the model to different scenarios such as unequal catchability [36], non closure of population [41], heterogenity accross sites [16] and temporary migration [12,43]).

Software development, means that even the complex models described in this paper are accessible to ecologist, meaning that maximum utility can be obtained from removal data.

There are several advantages for non-specialists that wish to apply removal methods: there is a vast array of available models for removal data, with the possibility of selecting the approach where the model assumptions best align with their particular study; there is no restriction to frequentist or Bayesian paradigms; there are several software packages and $\mathrm{R}$ code accompanying publications of more recent development to investigate where model assumption might fall short.

In our research we noted in earlier papers a thorough assessment of effects if model assumptions were violated but this rigour was not found in late methodological papers, except in some cases through part of a simulation. New methods developed in this research field have been motivated by unique aspects of particular data sets, and therefore nuances of a case study should be embraced rather than avoided in order to encourage methodological advances.

There is a worldwide interest in identifying tools for effective estimation of species population size and removal models show great potential for application in a wide range of situations, such as species relocation projects.

The potential of removal models to facilitate the estimation of population size in the source population whilst also obtaining a pool of individuals to translocate/reintroduce means that such models will remain important and will likely be further developed.

Species relocations are becoming more prevalent in conservation worldwide [144-146]. They are performed in several countries on an extensive range of species including plants [146], amphibians and reptiles [147,148]. There are many studies of translocated species and the success of reintroductions, including settlement, survival 
and reproduction of translocated individuals and their effects on the viability of the reintroduced population [149-154]. However, there is less information regarding the impact of translocations on the source or donor population $[155,156]$. These impacts can dramatically affect community stability, which is especially important when translocated individuals are from endangered populations [26]. The main components that can affect the stability of a population are: resistance, that is the ability to maintain its current state when subjected to a perturbation [157]; amplitude, that will determine, after some alteration, if it will return to its original state [158]; elasticity is the property that will determine the rate of return to its initial configuration when the perturbation exceeds the resistance of a community, but not its amplitude [158]. Removal data and removal models may be a powerful tool in order to understand and manage these populations.

\section{References}

1. Leslie PH, Davis DHS. An attempt to determine the absolute number of rats on a given area. The Journal of Animal Ecology. 1939, 8: 94-113.

2. Seber, GAF. The Estimation of Animal Abundance (2nd Edition). The Blackburn Press; 2002.

3. Eberhardt, LL. Appraising variability in population studies. Journal of Wildlife Management. 1978: 207-238.

4. Borchers, DL, Buckland, ST \& Zucchini, W. Estimating Animal Abundance: Closed Populations. Springer-Verlag, London; 2002

5. Otis, DL, Burnham, KP, White, GC, \& Anderson, DR. Statistical inference from capture data on closed animal populations. Wildlife monographs. 1978, 62: 3-135.

6. Bunrham, KP \& Overton, WS. Robust Estimation of Population Size When Capture Probabilities Vary Among Animals. Ecology. 1979; 60(5): 927-936.

7. Pollock, KH. Capture-recapture models: a review of current methods, assumptions and experimental design (Vol. 1308). Raleigh, NC: North Carolina State University; 1980.

8. Pollock, KH. A capture-recapture design robust to unequal probability of capture. The Journal of Wildlife Management. 1982; 46: 752-757.

9. Buckland, ST. A modified analysis of the Jolly-Seber capture-recapture model. Biometrics. 1980: 419-435.

10. Royle, JA \& Dorazio, RM. Hierarchical models of animal abundance and occurrence. Journal of Agricultural Biological and Environmental Statistics. 2006; 11: 249-263.

11. Williams, BK, Nichols JD \& Conroy, MJ. Analysis and Management of Animal Populations. Academic Press, New York; 2002.

12. Zhou, M, McCrea, RS, Matechou, E, Cole, DJ, \& Griffiths, RA. Removal models accounting for temporary emigration. Biometrics. 2019; 75: 24-35.

13. Zippin, C. The removal method of population estimation. The Journal of Wildlife Management. 1958; 22: 82-90.

14. Huggins, RM, \& Yip, PS. Statistical analysis of removal experiments with the use of auxillary variables. Statistica Sinica. 1997: 705-712. 
15. Chee, YE, \& Wintle, BA. Linking modelling, monitoring and management: an integrated approach to controlling overabundant wildlife. Journal of Applied Ecology. 2010; 47(6): 1169-1178.

16. Dorazio, DM, Jelks, HL \& Jordan, F. Improving removal-based estimates of abundance by sampling a population of spatially distinct subpopulations. Biometrics. 2005; 61: 1093-1101.

17. Hsieh, YH, Chen, CW, \& Lee, SM. Empirical Bayes approach to estimating the number of HIV infected individuals in hidden and elusive populations. Statistics in medicine. 2000; 19: 3095-3108.

18. Hsieh, YH, Chen, CW, Lee, SM, Chen, YMA, Wu, SI, Lai, SF \& Chang, AL. Estimating the Number of HIV-infected gay sauna patrons in Taipei area. Physica A: Statistical Mechanics and its Applications. 2006; 362: 495-503.

19. Hsieh, YH, de Arazoza, H, Lee, SM \& Chen, CW. Estimating the number of Cubans infected sexually by human immunodeficiency virus using contact tracing data. International journal of epidemiology. 2002; 31: 679-683.

20. Davis, AJ, Hooten, MB, Miller, RS, Farnsworth, ML, Lewis, J, Moxcey, M, \& Pepin, KM. Inferring invasive species abundance using removal data from management actions. Ecological Applications. 2016; 26: 2339-2346.

21. Germano, JM, Field, KJ, Griffiths, RA, Clulow, S, Foster, J, Harding, G \& Swaisgood, RR. Mitigation-driven translocations: Are we moving wildlife in the right direction? Frontiers in Ecology and the Environment. 2015; 13: 100-105.

22. St. Clair, K, Dunton, E \& Giudice, J. A comparison of models using removal effort to estimate animal abundance. Journal of Applied Statistics. 2013; 40: 527-545.

23. Moran, PAP. A mathematical theory of animal trapping. Biometrika. 1951; 38: 307-311.

24. Zippin, C. An evaluation of the removal method of estimating animal populations. Biometrics. 1956; 12: 163-189.

25. Moher, D, Liberati, A, Tetzlaff, J, \& Altman, DG. Preferred reporting items for systematic reviews and meta-analyses: the PRISMA statement. Annals of internal medicine. 2009; 151: 264-269.

26. Colomer, MÀ, Oliva Vidal, P, Jiménez, J, Martínez, JM, \& Margalida, A. Prioritizing among removal scenarios for the reintroduction of endangered species: insights from bearded vulture simulation modeling. Animal Conservation. 2019.

27. DeLury, DB. On the estimation of biological populations. Biometrics. 1947; 3 : 145-167.

28. Hayne, DC (1949). An examinaton of the strip census method for estimating animal populations. Journal of Wildlife Management. 1949; 13: 145-157.

29. Seber, GAF \& Le Cren, ED. Estimating Population Parameters from Catches Large Relative to the Population. Journal of Animal Ecology. 1967; 36: 631-643.

30. Schnute, J. A new approach to estimating populations by the removal method. Canadian Journal of Fisheries and Aquatic Sciences. 1983; 40: 2153-2169. 
31. Caughley, G. Analysis of certebrate populations. Wiley. 1977.

32. Seber, GAF \& Whale, JF (1970). The removal method for two and three samples. Biometrics, 26, 393-400.

33. Bedrick, EJ. Maximum-likelihood estimation for the removal method. The Canadian Journal of Statistics. 1994; 22(2): 285-293.

34. Hirst, D. An improved removal method for estimating animal abundance. Biometrics. 1994; 50(2): 501-505.

35. Bravo, R, Soriguer, MC, Villar, N, \& Hernando, JA. A simple method to estimate the significance level of the catch probability in the catch removal method in river fish populations. Fisheries research. 1999; 44(2): 179-182.

36. Carle, FL, \& Strub, MR. A new method for estimating population size from removal data. Biometrics. 1978; 34: 621-630.

37. Gatz, AJ, \& Loar, JM. Petersen and removal population size estimates: combining methods to adjust and interpret results when assumptions are violated. Environmental Biology of Fishes. 1988; 21: 293-307.

38. Roff, DA. On the accuracy of some mark-recapture estimators. Oecologia. 1973; 12: $15-34$.

39. van Poorten, BT, Barrett, B, Walters, CJ and Ahrens, RNM. Are removal-based abundance models robust to fish behavior? Fisheries Research. 2017; 196: $160-169$.

40. Skalski, JR, \& Robson, DS. A mark and removal field procedure for estimating population abundance. The Journal of Wildlife Management. 1982; 46: 741-751.

41. Matechou, E, McCrea, RS, Morgan, BJT, Nash, DJ \& Griffiths, RA. Open models for removal data. Annals of Applied Statistics. 2016; 10: 1572-1589.

42. Zucchini, W, MacDonald, IL \& Langrock, R. Hidden Markov models for time series Chapman \& Hall/CRC press. 2016.

43. Link, WA, Converse, SJ, Yackel, AA \& Hostetter, NJ. Analysis of population change and movement using robust design removal data. Journal of Agricultural Biological and Environmental Statistics. 2018; 23: 463-477.

44. Kelker, GH. Estimating deer populations by a differential hunting loss in the sexes. Utah Academy of Science and Art Letters. 1940; 17: 6-69.

45. Paulik, GJ \& Robson, DS. Statistical Calculations for Change-in-Ratio Estimators of Population Parameters Journal of Wildlife Management. 1969; $33(1): 1-27$.

46. Katsanevakis, S, Weber, A, Pipitone, C, Leopold, M, Cronin, M, Scheldat, M, Doyle, TK, Buhl-Mortensen, P, D'Anna, G, de Bools, I, Dalpadado, P, Damalas, D, Florentino, F, Garafalo, G, Glacalne, VM, Hawley, KL, Issaris, Y, Jansen, J, Knight, CM, Knittwels, L, Kronke, I, Mirto, S, Muxika, I, Reiss, H., Skjoldal, HR \& Voge, S. Monitoring marine populations and communities: methods dealing with imperfect detectability. Aquatic Biology. 2012; 16: 31-52.

47. North, PM \& Morgan, BJT. Modelling heron survival using weather data. Biometrics. 1979; 35: 667-682. 
48. Udevitz, MS \& Pollock, KH. Using Effort Information with Change-in-Ratio Data for Population Estimation. Biometrics. 1995; 51: 471-481.

49. Chao, A \& Chang, SH. An estimating function approach to the inference of catch-effort models. Environmental and Ecological Statistics. 1999; 6: 313-334.

50. Eberhardt, LL. Calibrating an index using removal data. Journal of Wildlife Management. 1982; 46: 734-740.

51. Ihde, TF, Hoenig, JM \& Frusher, SD. An index-removal abundance estimator that allows for seasonal change in catchability, with application to southern rock lobster Jasus edwardsii. Transactions of the American Fisheries Society. 2008; 38(1): 720-735.

52. Routledge, RD. The Removal Method for Estimating Natural Populations: Incorporating Auxiliary Information. Biometrics. 1989; 45(1): 111-121.

53. Golding, JD, \& Dreitz, VJ. Comparison of removal based methods for estimating abundance of five species of prairie songbirds. Journal of Field Ornithology. 2016; 87(4): 417-426.

54. Wang, Y \& Yip, PSF. An extension of the Lin-Yip estimator for continuous-time capture studies. Journal of Agricultural, Biological and Environmental Statistics. 2002; 7(4): 574-585.

55. Liu, L, Yip, PSF \& Watson, RK. Removal process estimation of population size for a population with known sex ratio. Environmental and Ecological Statistics. 2003; 10: 281-292.

56. Liu, L \& Yip, PSF. Estimating population size in proportional trapping-removal models. Statistica Sinica. 2003; 13: 243-254.

57. You, N \& Liu, L. Proportional trapping-removal model with a known ratio. Communications in Statistics - Theory and Methods. 2006; 35(1): 33-41.

58. Zipkin, EF \& Saunders, SP. Synthesizing multiple data types for biological conservation using integrated population models. Biological Conservation. 2018; 217: $240-250$.

59. Liu, L \& Yip, PSF. Proportional trapping-removal models with contaminated data. Journal of Statistical Planning and Inference. 2005; 127: 131-142.

60. Royle, JA. N-Mixture models for estimating population size from spatially replicated counts. Biometric. 2004; 60: 108-115.

61. Wormack, KM, Amelon, SK, Thompson III, F.R. \& LeBrun, J.J. Performance of hierarchical abundance models on simulated bat capture data. Acta Chiropterologica. 2018; 20(2): 465-474.

62. Dennis, E, Morgan, BJT \& Ridout, MS. Computational aspects of N-mixture models. Biometrics. 2014; 71: 237-246.

63. Haines, L. Multinomial N-mixture models for removal sampling. Biometrics, In press. 2019.

64. Bohrmann, TF, \& Christman, MC. Optimal allocation of sampling effort in depletion surveys. Journal of agricultural, biological, and environmental statistics. 2013; 18(2): 218-233. 
65. Zhou, M. Statistical Development of Ecological Removal Models. (PhD Thesis, University of Kent). 2018.

66. Farnsworth, GL, Pollock, KH, Nichols, JD, Simons, TR, Hines, JE, \& Sauer, JR. A removal model for estimating detection probabilities from point-count surveys. The Auk. 2002; 119: 414-425.

67. Bar, J, Droege, S, Geissler, P, Peterjohn, B \& Ralph, CJ. Density estimation in wildlife surveys. Wildlife Society Bulletin. 2004; 32(4): 1242-1247.

68. Amundson, CL, Royle, JA, \& Handel, CM. A hierarchical model combining distance sampling and time removal to estimate detection probability during avian point counts. The Auk. 2014; 131: 476-494.

69. MacKenzie, DI \& Royle, JA. Designing occupany studies general advice and allocation of survey effort. Journal of Applied Ecology. 2005; 42: 1105-1114.

70. Rota, CT, Fletcher, RJ, Dorazio, RM \& Betts, MG. Occupancy estimation and the closure assumption. Journal of Applied Ecology. 2009; 46: 1173-1181.

71. Chandler, RB, Royle, JA \& King, DI. Inference about density and temporary emigration in unmarked populations. Ecology. 2011; 92; 1429-1435.

72. Moore, JE, Scheiman, DM, \& Swihart, RK. Field comparison of removal and modified double-observer modeling for estimating detectability and abundance of birds. The Auk (2004; 121(3): 865-876.

73. Stanley, TR, \& Skagen, SK. Estimating the breeding population of long billed curlew in the United States. The Journal of Wildlife Management. 2007; 71(8): 2556-2564.

74. Thompson III, FR, \& La Sorte, FA. Comparison of methods for estimating bird abundance and trends from historical count data. The Journal of Wildlife Management. 2008; 72(8): 1674-1682.

75. Jones, SL, Nations, CS, Fellows, SD, \& McDonald, LL. Breeding abundance and distribution of Long-billed Curlews (Numenius americanus) in North America. Waterbirds. 2008; 31(1): 1-14.

76. Handel, CM, Swanson, SA, Nigro, DA, \& Matsuoka, SM. Estimation of avian population sizes and species richness across a boreal landscape in Alaska? The Wilson Journal of Ornithology. 2009; 121(3): 528-548.

77. McConnell, S, O’Connell, TJ, Leslie, Jr, DM, \& Shackford, JS. Mountain Plovers in Oklahoma: distribution, abundance, and habitat use. Journal of Field Ornithology. 2009; 80(1): 27-34.

78. Barbraud, C, Delord, K, Marteau, C, \& Weimerskirch, H. Estimates of population size of white chinned petrels and grey petrels at Kerguelen Islands and sensitivity to fisheries. Animal Conservation. 2009; 12(3): 258-265.

79. Reid, SM, \& Devlin, J. Effectiveness of stream sampling methods in capturing non-native Rusty Crayfish (Orconectes rusticus) in Ontario. The Canadian Field-Naturalist. 2014; 128(2): 111-118.

80. Saracco, JF, Siegel, RB, \& Wilkerson, RL. Occupancy modeling of Black backed Woodpeckers on burned Sierra Nevada forests. Ecosphere. 2011; 2(3): 1-17. 
81. Murray, LD, Gates, RJ, \& Spinola, RM. Evaluation of three methods to estimate density and detectability from roadside point counts. The Journal of Wildlife Management. 2011; 75(5): 1072-1081.

82. Sólymos P, Matsuoka SM, Bayne EM, Lele SR, Fontaine P, Cumming SG, Stralberg D, Schmiegelow FK, Song SJ. Calibrating indices of avian density from nonstandardized survey data: Making the most of a messy situation. Methods in Ecology and Evolution. 2013 Nov;4(11):1047-58.

83. Twedt, DJ. Estimating regional landbird populations from enhanced North American breeding bird surveys. Journal of Field Ornithology. 2015; 86(4): 352-368.

84. Good, I. J., Lewis, B.C., Gaskins, R.A. \& Howell, L. W. Population estimation by the removal method assuming proportional trapping. Biometrika. 1979; 66(3): $485-94$.

85. Nolte, E., Bart, J., Pauli, B., Kaltenecker, G., \& Heath, J. Detectability of migrating raptors and its effect on bias and precision of trend estimates. Avian Conservation and Ecology. 2016; 11(2).

86. Twedt, D. J., \& Wilson, R. R. Breeding birds in managed forests on public conservation lands in the Mississippi Alluvial Valley. Forest ecology and management. 2017; 384: 180-190.

87. Chaves, W. A., Sieving, K. E., \& Fletcher Jr, R. J. Avian responses to reduced-impact logging in the southwestern Brazilian Amazon. Forest ecology and management. 2017; 384: 147-156.

88. Matseur, E. A., Thompson III, F. R., Dickerson, B. E., Rumble, M. A., \& Millspaugh, J. J. Black backed woodpecker abundance in the Black Hills. The Journal of Wildlife Management. 2018; 82(5): 1039-1048.

89. Sólymos, P., S. M. Matsuoka, S. G. Cumming, D. Stralberg, P. Fontaine, F. K. A. Schmiegelow, S. J. Song, \& E. M. Bayne. Evaluating time-removal models for estimating availability of boreal birds during point-count surveys: sample size requirements and model complexity. Condor. 2018; 120: 765-786.

90. Mizel, J. D., Mcintyre, C. L., Lewis, S. B., Lindberg, M. S., \& Schmidt, J. H. A multi state, time removal model for population dynamics of cliff nesting raptors. The Journal of Wildlife Management. 2018; 82(8): 1701-1710.

91. Kellner, K. F. Local-scale Habitat Components Driving Bird Abundance in Eastern Deciduous Forests. The American Midland Naturalist. 2018; 180(1): $52-66$.

92. Matseur, E. A., Millspaugh, J. J., Thompson III, F. R., Dickerson, B. E., \& Rumble, M. A. The importance of disturbance and forest structure to bird abundance in the Black Hills. The Condor: Ornithological Applications. 2019; $121(1)$.

93. Peterson, J., Taylor, M., \& Hanson, A. Leslie population estimate for a large lake. Transactions of the American Fisheries Society. 1980; 109(3): 329-331.

94. Jones, M. L., \& Stockwell, J. D. Statistical analysis of removal experiments with the use of auxillary variables. North American Journal of Fisheries Management. 1997; 15(3): 551-562. 
95. Zamora, L., Saavedra, D., \& Moreno-Amicht, R. Stock assesment, biomass and fish production in two mediterranean basins (NE Spain). Limnetica. 1996; 12 : 47-58.

96. Feunteun, E., Acou, A., Guillouët, J., Laffaille, P. \& Legault, A. Spatial distribution of an eel population (Anguilla anguilla L.) in a small coastal catchment of Northern Brittany (France). Consequences of hydraulic works. Bulletin Français de la Pêche et de la Pisciculture.1998; 349; 129-139.

97. Brownie, C. \& Robson, D. S. Estimation of time-specific survival rates from tag-resighting samples: a generalization of the Jolly-Seber model. Biometrics. 1983; 39: 437-453.

98. Finstad, A. G., Jansen, P. A. \& Langeland, A. Gillnet selectivity and size and age structure of an alpine Arctic char (Salvelinus alpinus) population. Canadian Journal of Fisheries and Aquatic Sciences. 2000; 57(8): 1718-1727.

99. Rosenberger, A. E. \& Dunham, J. B. Validation of abundance estimates from mark-recapture and removal techniques for rainbow trout captured by electrofishing in small streams. North American Journal of Fisheries Management. 2005; 25(4): 1395-1410.

100. Baumgartner, L. J. Population estimation methods to quantify temporal variation in fish accumulations downstream of a weir. Fisheries Management and Ecology. 2006; 13(6): 355-364.

101. Dauwalter, D. C., \& Fisher, W. L. Electrofishing capture probability of smallmouth bass in streams . North American Journal of Fisheries Management. 2007; 27(1): 162-171.

102. Rivot, E., Prévost, E., Cuzol, A., Baglinière, J. L., \& Parent, E. Hierarchical Bayesian modelling with habitat and time covariates for estimating riverine fish population size by successive removal method. Canadian Journal of Fisheries and Aquatic Sciences. 2008; 65(1): 117-133.

103. Booth, A. J., Traasg, G. R., \& Weyl, O. L. Adult African sharptooth catfish, Clarias gariepinus, population dynamics in a small invaded warm-temperate impoundment. African Zoology. 2010; 45(2): 299-308.

104. Meyer, K. A., \& High, B. Accuracy of removal electrofishing estimates of trout abundance in Rocky Mountain streams. North American Journal of Fisheries Management. 2011; 31(5): 923-933.

105. Reidy, J. L., Thompson III, F. R., \& Bailey, J. W. Comparison of methods for estimating density of forest songbirds from point counts. The Journal of Wildlife Management. 2011; 75(3): 558-568.

106. Yüksel, F., Alp, A., Gündüz, F., Çoban, M. Z., \& Demirol, F. Estimation of the population size of Capoeta umbla (heckel, 1843) in the Lake Hazar (Elazig) by removal method. Journal of Nanomaterials and Biostructures. 2014; 9(1): 167-174.

107. Mazzoni, R., da Silva, R. C., \& Pinto, M. P. Invasion and colonisation of a tropical stream by an exotic loricariid fish: indices of gradual displacement of the native common pleco (Hypostomus punctatus) by the red fin dwarf pleco (Parotocinclus maculicauda) over fifteen years. PloS one. 2015; 10(10): e0139968. 
108. Koenig, M. K., Meyer, K. A., Kozfkay, J. R., DuPont, J. M., \& Schriever, E. B. Evaluating the ability of tiger muskellunge to eradicate Brook Trout in Idaho alpine lakes. North American Journal of Fisheries Management. 2015; 35(4): 659-670.

109. Harris, J. E., Jolley, J. C., Silver, G. S., Yuen, H., \& Whitesel, T. A. An experimental evaluation of electrofishing catchability and catch depletion abundance estimates of larval lampreys in a wadeable stream: use of a hierarchical approach. Transactions of the American Fisheries Society. 2016; 145(5): 1006-1017.

110. Tanir, Ö. Z. \& Korkmaz, A. Ş. Density and Biomass of Fish Populations in Kirmir Stream of Sakarya. Journal of Agricultural Sciences. 2016.

111. Zeh, J. E., Ko, D., Krogman, B. D., \& Sonntag, R. A multinomial model for estimating the size of a whale population from incomplete census data. Biometrics. 1986: 1-14.

112. Raftery, A. E., \& Zeh, J. E. Estimating bowhead whale population size and rate of increase from the 1993 census. Journal of the American Statistical Association. 1998; 93(442): 451-463.

113. Rainbolt, R. E., \& Coblentz, B. E. Restoration of insular ecosystems: control of feral goats on Aldabra Atoll, Republic of Seychelles. Biological Invasions. 1999; 1(4): 363-375.

114. Andrea, D., Gentile, R., Maroja, L. S., Fernandes, F. A., Coura, R., \& Cerqueira, R. Small mammal populations of an agroecosystem in the Atlantic Forest domain, southeastern Brazil. Brazilian Journal of Biology. 2007; 67(1): 179-186.

115. Haskell, S. P. Validity of hunter surveys for daily effort and deer sightings in Vermont. Wildlife Society Bulletin. 2011; 35(4): 438-444.

116. Keech, M. A., Taras, B. D., Boudreau, T. A., \& Boertje, R. D. Black bear population reduction and recovery in western Interior Alaska. Wildlife Society Bulletin. 2014; 38(1): 71-77.

117. Byrne, A. W., O’Keeffe, J., Sleeman, D. P., Davenport, J., \& Martin, S. W. Impact of culling on relative abundance of the European badger (Meles meles) in Ireland. European journal of wildlife research. 2013; 59(1): 25-37.

118. Fleming, H. L., Jones, J. C., Belant, J. L., \& Richardson, D. M. Probability of Detection and Visual Count Error for Rafinesque's Big-eared Bat (Corynorhinus rafinesquii) and Southeastern myotis (Myotis austroriparius) in Tree Cavities. The American Midland Naturalist. 2013: 169(1): 56-66.

119. Hussain, I. The level of rodent problems in poultry farms of Rawalpindi-Islamabad, Pakistan. Mammalia. (2016; 80(2): 193-204.

120. Parra, G. J., \& Cagnazzi, D. Conservation status of the Australian humpback dolphin (Sousa sahulensis) using the IUCN Red List Criteria. Advances in marine biology. 2016; Vol. 73: 157-192. Academic Press.

121. Davis, A. J., Leland, B., Bodenchuk, M., VerCauteren, K. C., \& Pepin, K. M. Estimating population density for disease risk assessment: the importance of understanding the area of influence of traps using wild pigs as an example. Preventive veterinary medicine. 2017; 141: 33-37. 
122. Lampo, M., \& Bayliss, P. Density estimates of cane toads from native populations based on mark-recapture data. Wildlife Research. 1996; 23(3): 305-315.

123. Salvidio, S. Estimating abundance and biomass of a Speleomantes strinatii (Caudata, Plethodontidae) population by temporary removal sampling. Amphibia-Reptilia. 1998;19(2): 113-124.

124. Salvidio, S. Population dynamics and regulation in the cave salamander Speleomantes strinatii. Naturwissenschaften. 2007; 94(5): 396-400.

125. Louette, G., Devisscher, S. \& Adriaens, T. Control of invasive American bullfrog Lithobates catesbeianus in small shallow water bodies. European Journal of Wildlife Research. 2013; 59(1): 105-114.

126. Göçmen, B., Cicek, K., Akman, B., Oğuz, M. A. \& Yalçınkaya, D. Population size estimates of Lissotriton vulgaris (L., 1758) and Triturus ivanbureschi Arntzen \& Wielstra 2013 (Caudata: Salamandridae) from Edirne, European part of Turkey. North-Western Journal of Zoology. 2015; 11(2).

127. Romano, A., Anderle, M., Forti, A., Partel, P. \& Pedrini, P. Population density, sex ratio and body size in a population of Salamadra atra atra on the Dolomites. Acta Herpetologica. 2018; 13(2): 195-199.

128. Peterson, J. T., Thurow, R. F., \& Guzevich, J. W. An evaluation of multipass electrofishing for estimating the abundance of stream dwelling salmonids. Transactions of the American Fisheries Society. 2004; 133(2): 462-475.

129. Gowan, C. \& Knisley, C. B. Distribution, abundance and conservation of the highly endemic Coral Pink Sand Dunes tiger beetle, Cicindela albissima Rumpp. Biodiversity. 2014; 15(2-3): 119-129.

130. Akhoundi, M., Jourdain, F., Chandre, F., Delaunay, P. \& Roiz, D. Effectiveness of a field trap barrier system for controlling Aedes albopictus: a "removal trapping" strategy. Parasites \& vectors. 2018; 11(1): 101.

131. Elliott, J. M. Population size, weight distribution and food in a persistent population of the rare medicinal leech, Hirudo medicinalis. Freshwater Biology. $2008 ; 53(8)$ : 1502-1512.

132. Prescott, J., Vogel, C., Pollock, K., Hyson, S., Oktaviani, D. \& Panggabean, A. S. Estimating sea cucumber abundance and exploitation rates using removal methods. Marine and Freshwater Research. 2013; 64(7): 599-608.

133. Baillargeon, S. \& Rivest, L.P. Rcapture: loglinear models for capture-recapture in R. Journal of Statistical Software. 2007; 19(5): 1-31.

134. R Core Team. R: A language and environment for statistical computing. R Foundation for Statistical Computing, Vienna, Austria. 2017 https://www.R-project.org/.

135. White, G.C. \& Burnham, K.P. Program MARK: survival estimation from populations of marked animals. Environmental and Ecological Statistics. 1999; 15(1): 89-99.

136. White, G.C. Closed population estimation models and their extensions in Program MARK. Bird study. 2008; 46(sup1): S120-S139. 
137. Featherman, E. R. \& Lepak, J. M. Addressing depletion failure and estimating gear efficiency using back-calculation of capture probabilities. Fisheries Research. 2013; 147: 284-289.

138. Laake, J.L., Borchers, D., Thomas, L., Miller, D. \& Bishop, J. mrds: Mark-recapture distance sampling. R package version, 2. 2015.

139. Laake, J.L., Johnson, D. S. \& Conn, P. B. marked: An R package for maximum-likelihood and MCMC analysis of capture-recapture data. Methods in Ecology and Evolution. 2013; 4: 885-890.

140. Fiske, I. \& Chandler, R. unmarked: An R Package for Fitting Hierarchical Models of Wildlife Occurrence and Abundance. Journal of Statistical Software. 2011; 43(10): 1-23.

141. Seaby, R. M. H. \& RHenderson, P. A. Removal Sampling 2. Pisces Conservation Ltd., Lymington, England. 2007.

142. MacKenzie, D. \& Hines, J. RPresence: R Interface for Program PRESENCE. R package version 1.1.1. 2015.

143. Miller, D.L., Rexstad, E., Thomas, L., Marshall, M. \& Laake, J. L. Distance Sampling in R. Journal of Statistical Software. 2019; 89: 1-28.

144. Seddon P. J., Armstrong D. P. \& Maloney R. F. SDeveloping the science of reintroduction biology. Conserv. Biol. 2007; 21: 303-12.

145. Bajomi B., Pullin A. S., Stewart G. B. \& Takács-Sánta A. Bias and dispersal in the animal reintroduction literature. Oryx. 2010; 44: 358-65.

146. Godefroid, S., Piazza, C., Rossi, G., Buord, S., Stevens, A.D., Aguraiuja, R., Cowell, C., Weekley, C.W., Vogg, G., Iriondo, J.M. \& Johnson, I. How successful are plant species reintroductions? Biological Conservation. 2011; 144(2): 672-682.

147. Dodd C. K. J. \& Seigel R.A. Relocation, repatriation, and translocation of amphibians and reptiles: are they conservation strategies that work?

Herpetologica. 1991; 47: 336-350.

148. Germano J. M. \& Bishop P. J. Suitability of Amphibians and Reptiles for Translocation. Conserv. Biol. 2009; 23: 7-15.

149. Sarrazin, F. \& Legendre, S. Demographic approach to releasing adults versus young in reintroductions. Conserv. Biol. 2000; 14: 488-500.

150. Armstrong, D.P. \& Seddon, P.J. Directions in reintroduction biology. Trend Ecol. Evol. 2008; 23: 20-25.

151. Le Gouar, P., Robert, A., Choisy, J.-P., Henriquet, S., Lecuyer, P., Tessier, C. \& Sarrazin, F. Roles of survival and dispersal in reintroduction success of griffon vulture (Gyps fulvus). Ecol. Appl. 2008; 18: 859-872.

152. Mihoub, J.-B., Prince, K., Duriez, O., Lecuyer, P., Eliotout, B. \& Sarrazin, F. Comparing the effects of release methods on survival of the Eurasian black vulture Aegypius monachus reintroduced in France. Oryx. 2013; 48: 106-115.

153. Robert, A., Colas, B., Guigon, I., Kerbiriou, C., Mihoub, J.- B., Saint-Jalme, M. \& Sarrazin, F. SDeveloping the science of reintroduction biology. Anim. Conserv. 2015; 18: 397-406. 
154. Bertolero, A., Pretus, J.L. \& Oro, D. The importance of including survival release costs when assessing viability in reptile translocations. Biol. Conserv. 2018; 217: 311-320.

155. McCleery, R., Hostetler, J.A. \& Oli, M.K. Better off in the wild? Evaluating a captive breeding and release program for the recovery of an endangered rodent. Biol. Conserv. 2014; 169: 198-205.

156. Margalida, A., Colomer, M.A., Oro, D., Arlettaz, R. \& Donazar, J.A. Assessing the impact of removal scenarios on population viability of a threatened, long-lived avian scavenger. Sci. Rep. 2015; 5: 16962.

157. Boesch D.F. Diversity, stability and response to human disturbance in estuarine ecosystems. In: Structure, functioning and management of ecosystems. Proc First Int Congr Ecol. PUDOC. Wageningen. 1974: 109-114.

158. Orians G.H. Diversity, stability and maturity in natural ecosystems. In: van Dobben WH. Lowc-McConncll RH (eds) Unifying concepts in ecology. Junk. The Hague. 1974: 139-150. 


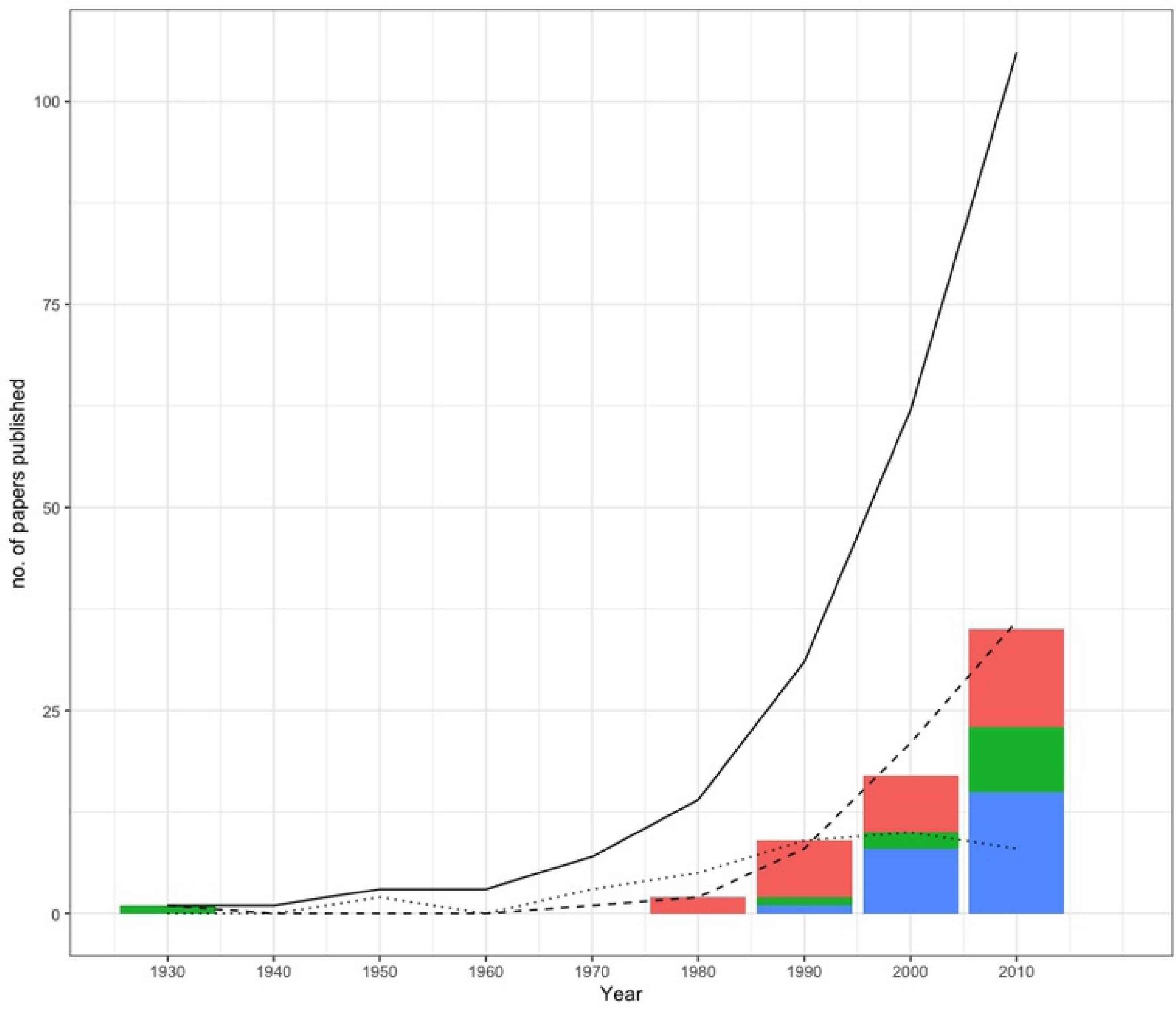

- Total cumulative

Goal

- - Application

.... Methodological

\section{Ecosystem}

aquatic
terrestrial
aerial

Figure2 


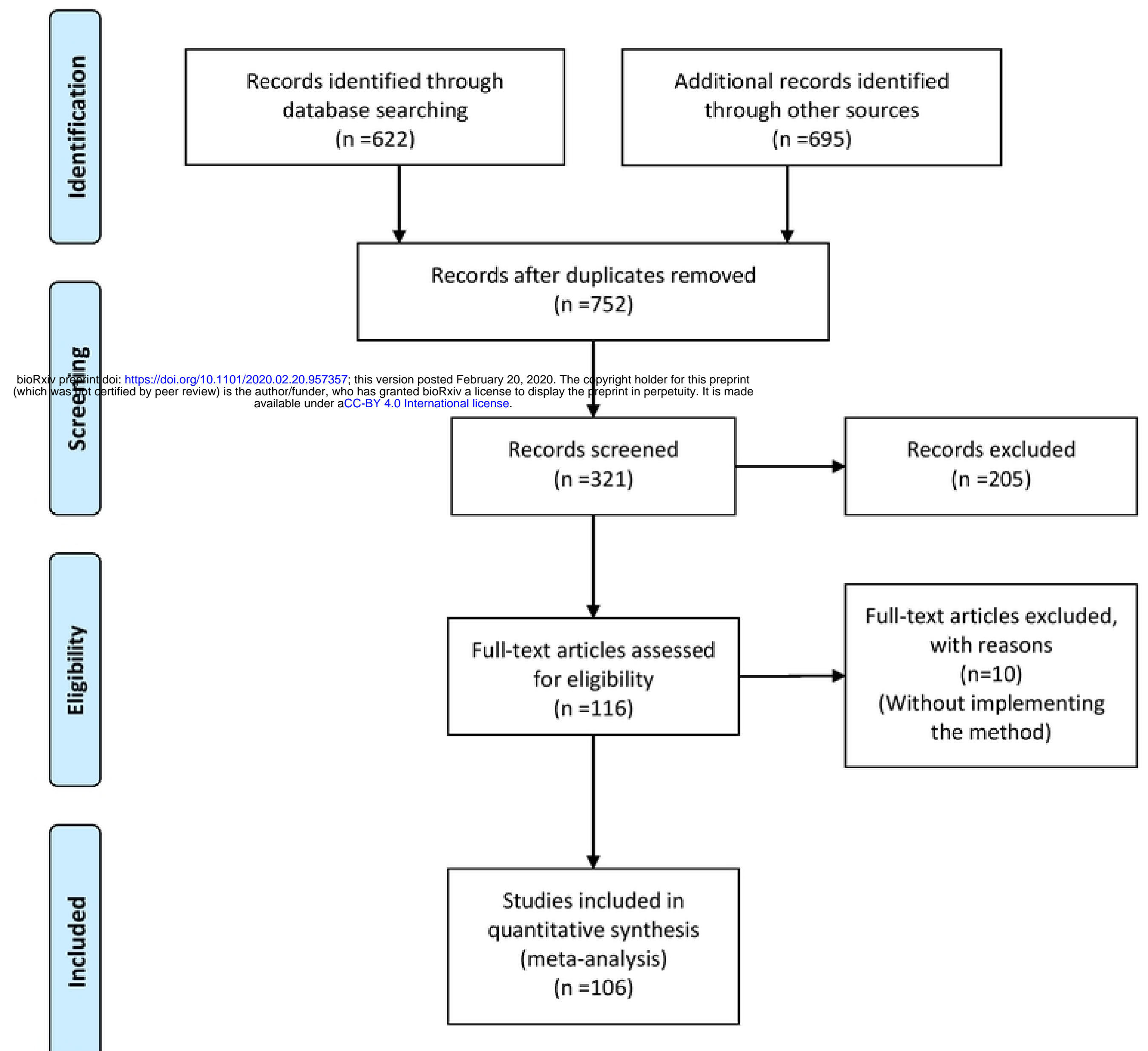

Figure 1 